\title{
More compatible with 'cryptic miliary tuberculosis'
}

Hong Kong Med J 2014;20:354

DOI: 10.12809/hkmj144317

To the Editor-I read with interest the case report published by Shea and Ip titled "Pulmonary tuberculosis complicating asbestosis". ${ }^{1}$ On reading the details, I could not agree on the authors' interpretation of the findings and the diagnosis of asbestosis. While it is beyond doubt that the findings of calcified pleural plaques point towards the diagnosis of a form of "asbestos-related pleural disease", this condition has to be distinguished from 'asbestosis' although the two conditions may coexist in some patients. Asbestosis refers to scarring of the lung parenchyma as a result of heavy asbestos exposure. Radiological features are usually in the form of reticulation, linear and curvilinear opacities, and parenchymal bands. ${ }^{2}$ These features were not obvious in the computed tomographic images shown. Rather, the prominent radiological findings were those of fine nodules which, in my view, were more compatible with a diagnosis of 'cryptic miliary tuberculosis. Cryptic miliary tuberculosis is a form of tuberculosis which tends to occur in the elderly and presents with fever of unknown origin with negative bacteriological findings. ${ }^{3}$ Diagnosis is difficult and often delayed. Given the clinical and radiological features of the case reported here, I think a more appropriate title would be "Cryptic miliary tuberculosis in an elderly patient with underlying asbestos-related pleural plaques".

CF Wong *, FRCP (Edin), FHKAM (Medicine)

TB and Chest Unit, Grantham Hospital, Aberdeen, Hong Kong

* Corresponding author: wongcf2001@yahoo.com.hk

\section{References}

1. Shea YF, Ip JJ. Pulmonary tuberculosis complicating asbestosis. Hong Kong Med J 2014;20:265.e3-5.

2. Roach HD, Davies GJ, Attanoos R, Crane M, Adams H, Phillips S. Asbestos: when the dust settles an imaging review of asbestos-related disease. Radiographics 2002;22:S167-84.

3. Yu YL, Chow WH, Humphries MJ, Wong RW, Gabriel M. Cryptic miliary tuberculosis. Q J Med 1986;59:421-8.

\section{Authors' reply}

To the Editor-We would like to thank Dr CF Wong for clarifying the terminologies used in our article. ${ }^{1}$ We apologise for not annotating the interstitial septal thickening in the original figures; furthermore, the resolution and greyscale of the images were not optimal to demonstrate the reticulations in our case. We have retrieved one of the baseline computed

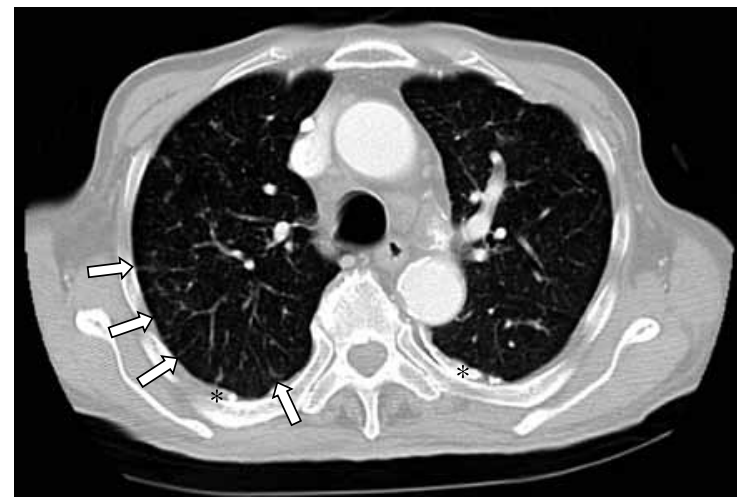

FIG. Baseline computed tomography (CT) thorax taken soon after admission ( 2 months before the second set of CT was performed). Calcified pleural plaques $(*)$ and areas of interstitial septal thickening and fibrosis (arrows) are shown

tomography (CT) images of the thorax of our patient to further demonstrate the presence of interstitial septal thickening on top of the calcified pleural plaques (Fig). These findings signify that our patient had lung parenchymal changes due to asbestos exposure, together with asbestos-related pleural plaques. ${ }^{2}$ Because of these parenchymal changes, the diagnosis of tuberculosis was challenging in the initial stage. We agree that 'cryptic pulmonary tuberculosis' is more specific than 'pulmonary tuberculosis' as the final diagnosis for our patient who presented with pyrexia of unknown origin but with apparently negative mycobacterial workup at the beginning while the interval CT thorax showed miliary shadows. ${ }^{3}$ Perhaps, 'Cryptic miliary tuberculosis in an elderly patient with asbestosis' would be an even more accurate and attractive title for this article. We would once again like to thank Dr Wong for sharing his ideas and experience with us.

${ }^{1}$ YF Shea *, MRCP (UK), FHKAM (Medicine)

Janice JK Ip, MB, BS, FRCR

${ }^{1}$ Department of Medicine

2 Department of Radiology

Queen Mary Hospital, The University of Hong Kong, Pokfulam, Hong Kong

* Corresponding author: elphashea@gmail.com

\section{References}

1. Shea YF, Ip JJ. Pulmonary tuberculosis complicating asbestosis. Hong Kong Med J 2014;20:265.e3-5.

2. Fishwick D, Barber CM. Non-malignant asbestos-related diseases: a clinical view. Clin Med 2014;14:68-71.

3. Yu YL, Chow WH, Humphries MJ, Wong RW, Gabriel M. Cryptic miliary tuberculosis. Q J Med 1986;59:421-8. 